\title{
AUTOMATION OF THE RESIDENTIAL BUILDING WATER SUPPLY SYSTEM PUMPING STATION
}

Kulia A.M., student ${ }^{1}$

${ }^{1}$ Odessa National Academy of Food Technologies, Odessa

Copyright (C) 2014 by author and the journal "Automation technological and business - processes". This work is licensed under the Creative Commons Attribution International License (CC BY). http://creativecommons.org/licenses/by/4.0/

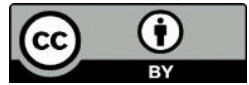

ONAFT

Open Access

DOI: $10.15673 /$

\begin{abstract}
Essence of process of water-supply of apartment dwelling house is considered. The existent state over of automation of the pumping stations is brought. The task of development of the effective system of automatic control is put by them. Possibility of decision of task is shown by the use in the system of frequency transformer that feeds the electrodrives of pumps, and also due to perfection of algorithms of the pumps rotation frequency adjusting and logical management of their switching a sequence. The practical value of the use of the system is to increase dynamic.
\end{abstract}

Keywords

Pumping station, water supply, residential building, energy saving, automatic control, dynamic precision control.

The relevance of the objectives of the study. The water supply system of an apartment building - a residential, hospital or sanatorium - objname is characterized by large water consumption. The water supply system are among the most expensive technological objects in utilities and industry. The biggest component of cost is energy consumption. Ukraine belongs to energy deficient countries. Therefore, energy savings deemed the most important direction of energy policy in Ukraine. Developed comprehensive state and regional energy efficiency programs. The second component of the carrying capacity is the amount of water, natural resources which are limited. The third component is an expensive technological equipment, especially piping systems, the durability of which depends on the frequency of occurrence of overloads. In this light, it naturally is actual scientific and technical problem of reducing the energy intensity of the technological process of water supply. The solution to this problem is achieved social and economic results that improve the lives of people, increase the economic capacity of the state, reduce environmental damage. This problem is solved mainly in two ways. The first of these is the use of more sophisticated technological and electrotechnical equipment, and the second is in the development of automation systems of pumping stations (NS), with the aim of improving the processes of control of technological equipment and improvement at the expense of the economic performance of the SV [1].

The essence of the technological process of water supply - targeted use of energy resources in the water system to provide water to the residential high-rise buildings.

The water supply system to provide connection to city water; water metering (water metering node); accumulation of reserve water storage to smooth out peak demand; rise of water on high; stablises water pressure in the system regardless of changes in discharge; gradual replacement of the volume of water in the tank savings; energy savings

The main task of pumping stations - maintain constant pressure in the water system in case of irregular water consumption. This is especially true during peak hours, when the water flow is maximum, this period usually falls on the morning and evening hours. Operation of the pumping station almost continuous - 24 hours a day. Therefore, prior to pumping stations, designed for apartment buildings, high requirements of reliability and quality [2].

For optimal water supply on the objects to ensure the smooth operation of the entire water system engineers actively practice the introduction of automation of pumping stations.

Automation in the pumping stations are controlled by the following functions:

- start/stop of pumps and other installations;

- control and regulation of parameters such as water level, flow, pressure and so on;

- the reception of signals about changing the parameters and transferring them into the controllers [3].

A review of the existing solutions.

There are many options of pumping stations, in particular, a complete pump station Wilo high pressure which uses 3 parallel connected high-pressure centrifugal pump. After the pumping station the water flows directly into the pipe network at 
home. To control the drives of the pumps system is used Wilo-Comfort [http://ovk.prom.ua/p1532359-nasosnaya-stantsiyawilo.html]. Depending on the water pressure in the system pumps are enabled or disabled sequentially.

However, this control system has drawbacks:

1. With the direct inclusion of electric drives of pumps capacity of $2.2 \mathrm{~kW}$ each few years fail contactors of electric drives for burning contacts.

2. When the pressure in the water system close to the boundary of the inclusion, one can observe the frequent on/off of the drive that leads to its heating. If not configured thermal protection of the motor can be damaged.

3. The apartments located on the upper floors of the house, the pressure varies significantly (up to 1 bar), leading to a realignment of the thermal mode when taking a shower.

Consider one of the variants of the automatic control system of pump station of water supply system of apartment houses, developed at the Department of automation of production processes ONAFT.

The goal of this research - is to build a control system of the pump station, which would eliminate these shortcomings and provide economical consumption of electricity. The goal was achieved through the use in the system of frequency Converter that feeds the electric drives of the pumps, and also by improving the algorithms speed control of pumps and control logic the sequence of their switching.

Known two systems pump station control using frequency Converter by using a constant or the shift supervisor of the PID - regulator [http://www.picad.com.ua/3403/pdf/26_30.pdf].

The study scheme was chosen with a permanent master UNDER the regulator, given its relative simplicity and hence greater reliability. It regulates the system pressure at home the pressure sensor signal, changing the frequency of rotation of a single pump with frequency Converter. When the pressure due to the increase of expenditure will fall to a certain level, you consistently will begin to turn on additional pumps direct inclusion.

For the implementation of the management system in its composition, in addition to the frequency Converter is further included a pressure sensor and a flow sensor with a continuous analog output signals. The pressure sensor will provide a feedback signal in the system, and the flow sensor is required to estimate the load, since the pressure of the water supply network depends significantly on costs.

The main functions of the developed control system:

1. Stabilization of the pressure in the water network at a predetermined level by changing the frequency of rotation of the first pump according to the PID-algorithm.

2. Improving the dynamic accuracy of pressure maintenance by adjusting the control signal depending on the change of the water flow.

3. Logic control of switching actuators of the second and third pump in case the first pump does not provide the required water flow.

4. Alarm about the critical values of water levels in the reservoir of accumulation, and minimum and Maksimalna values of water pressure in the suction and magnetosome the pipeline.

5. Lock pre-crash situations when the critical values rnv or pressure with the issuance of the warning beeps.

6. Display information about the system operator with the ability to switch operation modes and configuration parameters of the algorithms.

7. Data archiving proremote system in the form of necessary graphs.

8. Administration of SCADA-system.

\section{Analysis of technological process vodozabezpechenist as the object of regulation}

The aim of the pumping station is the provision in the house water with the pressure required at the lowest cost of electricity. This is achieved by maintaining a water pressure of Pв home network at 6 bar with long permissible deviations \pm 0.1 and transient \pm 4 for $30 \mathrm{C}$ when its variable costs during the day.

To minimize the cost of electricity by improving the dynamic accuracy of maintaining of $\mathrm{PB}(\mathrm{t})$ in time, and also due to the proximity Rsad to the lowest possible level, i.e. to the lower boundary pressure, which will be comfortable using cold water, especially on the upper floors. In the developed system to regulate the water pressure in the network by changing the pump speed, i.e. the control action U1 is the frequency of rotation of the inverter, which drives the pump.

As a controlled perturbation consider changes in water flow FB, which can be measured by flow meter.

To uncontrolled perturbations include changing the pressure in the urban network, but given the small values of these changes in the future to consider them will not, especially that most of the time the pump station is powered by water, which potratila in the suction pipe from the tank accumulation, and thus the pressure it is almost constant.

In the block diagram presents the own control channels and controlled disturbances (Fig.1)

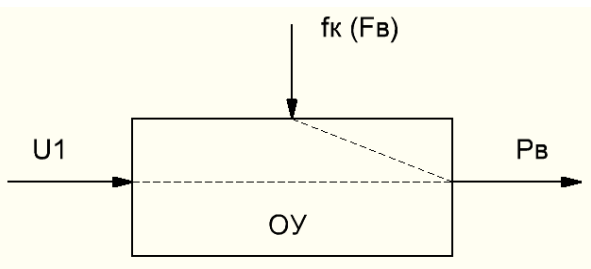


Fig. 1 Structural (coordinate) diagram of OU

It was investigated that the control channel has static properties, which are properties of self-regulation. During authentication, the controlled coordinate of the disturbances found that in them is significantly dominated by the random component.

\section{Development of control algorithms}

The main factors that affect the dynamic accuracy of the system is the effect of controlled perturbations, which arise due to load changes, i.e. changes in the water flow in a water network. The negative impact of these factors can be compensated by introducing in the structure of ACS corrective communication that will ensure the invariance relative to controlled disturbances.

It is known [Abstract of lectures on discipline "automatic control Theory" (part II)- Jobin V. A. OHAPC. Odessa - 2007] that one of the variants of constructing a system like this:

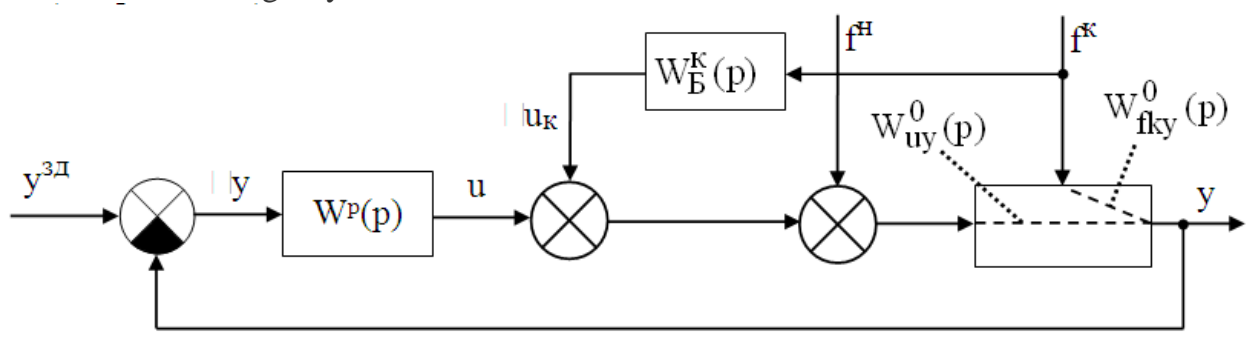

Fig. 2.- Structural diagram of the ACS is invariant with respect to the controlled disturbances

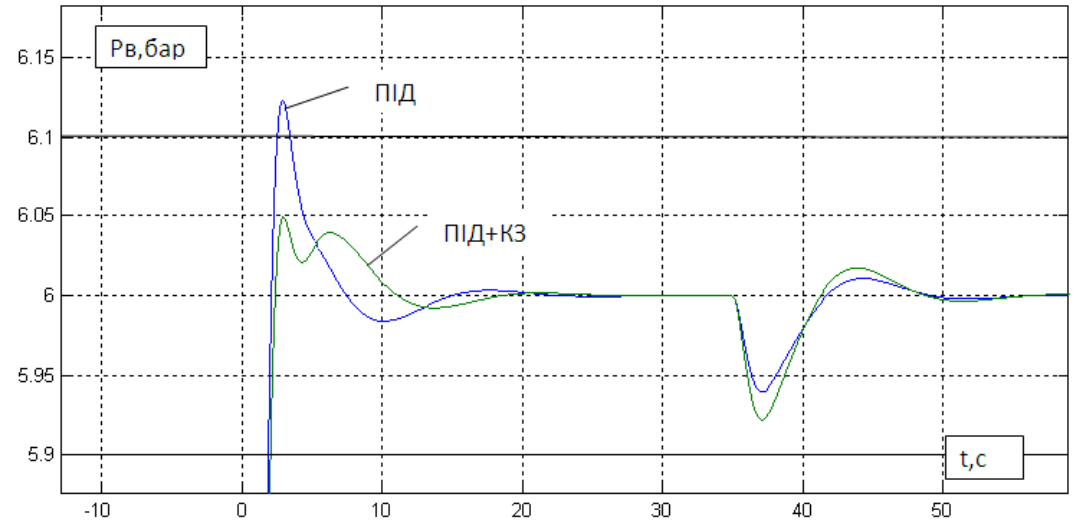

Fig. 3 - Graphical results of the comparison SAU more simple structure and SAU high dynamic accuracy

As a result of the synthesis of ACS is increased dynamic precision all the parameters of transient and steady-state modes satisfy allowable requirements.

The resulting optimal parametric synthesis of SAR high dynamic accuracy showed the best performance for both direct and integrated indicators of the quality compared to SAR with a PID controller and can be applied in practice when implementing the system pressure control in water supply networks at home.

It was also developed by the working place of operator-technologist of the system.

AWS of operator-technologist should provide the ability to perform the following operator functions:

- control values of technological parameters of water supply process and the assignment of control modes;

- monitoring the status of the equipment (on, off, is in the accident) and the value xploiting installation options;

- to manage the starting and stopping of the installation in manual and automatic control modes;

- control individual equipment of the installation in manual mode;

- to control the occurrence of irregularities in the operation of the equipment and operatively to react to them. 


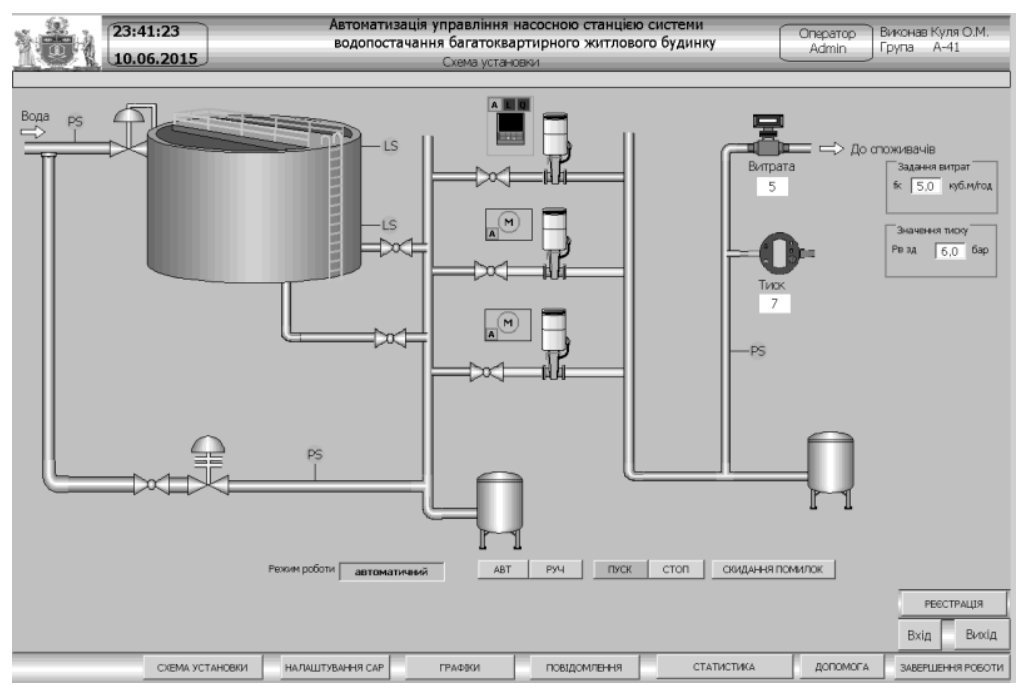

Fig. 4 - automated work place of operator-technologist

\section{Insights:}

1. The relevance of the research topic due to the severity of the problem of energy saving in Ukraine and, in particular, the tasks of energy saving in water supply systems.

2. For optimal water supply to the facilities, to ensure uninterrupted operation of water supply system actively practiced by introduction of automation of pumping stations.

3. To minimize the cost of electricity by improving the dynamic accuracy of maintaining of Ro(t) in time, and also due to the proximity Rsad to the lowest possible level.

4. The resulting optimal parametric synthesis of SAR high dynamic accuracy showed the best performance for both direct and integrated indicators of the quality compared to SAR with a PID controller and can be applied in practice when implementing the system pressure control in water supply networks at home.

\section{Referenses}

[1] Automated energy saving control of the pump station of water supply system / Gritsenko K. G.// author. dis..kand.tech.Sciences 05.13.07.-Donetsk - 2002

[2] http://dretun.ru/hardworking/voda/vodo-shema/

[3] http://chastotnik.com.ua/a-avtomatizatsiya-nasosnih-stantsiy-v-vodosnabzhenii

[4] http://ovk.prom.ua/p1532359-nasosnaya-stantsiya-wilo.html

[5] http://www.picad.com.ua/3403/pdf/26 30.pdf

[6] Konspekt kursa lektsiy po distsipline "Teoriya avtomaticheskogo upravleniya" (chast I)- Hobin V.A. OGAPT. Odessa $2007 \mathrm{~g}$. 